\title{
Corneal topographic changes following trans-conjunctival 20 gauge sutureless vitrectomy (TC20V)
}

This article was published in the following Dove Press journal:

Clinical Ophthalmology

21 April 2012

Number of times this article has been viewed

\author{
Ahmed Abdel Alim \\ Mohamed' \\ Mohamed Abdrabbo ${ }^{2}$ \\ 'Faculty of Medicine, Ophthalmology \\ Department, Ain Shames University, \\ Cairo, Egypt; ${ }^{2}$ Faculty of Medicine, \\ Ophthalmology Department, Benha \\ University, Benha, Egypt
}

Purpose: To assess the occurrence and magnitude of corneal topographic changes in phakic eyes undergoing Transconjuctival Cannulated 20 gauge Vitrectomy (TC20V) without scleral buckling or silicone oil tamponade.

Setting: Prospective randomized controlled study done at Egyptian Eye Academy.

Methods: Forty eyes of 40 patients underwent TC20V for a variety of vitreo-retinal conditions over a 1 year follow-up period. Corneal keratometric readings were obtained using Oculus Pentacam before surgery, 1 week after, and 1 month after surgery; neither scleral buckling nor silicone oil tamponade were used in order to not affect the final corneal changes. Cases with postoperative hypotony were excluded.

Results: The mean preoperative K1 (vertical keratometry) was $44.87 \pm 3.55$, the mean preoperative K2 (horizontal keratometry) was $44.57 \pm 3.68$; the mean postoperative $\mathrm{K} 1$ after 1 week was $45.1 \pm 6.82$ while the mean postoperative K2 after 1 week was $45.7 \pm 3.97$. Using paired $t$-test analysis, the $P$-value of the $\mathrm{K} 1$ change was 0.01 and $P$-value of the $\mathrm{K} 2$ change was 0.02 . Both indicate minimally significant differences. One month postoperative the mean K1 was $45.2 \pm 2.53$ and the mean $\mathrm{K} 2$ was $45.1 \pm 1.56$ and $P$-values of both $\mathrm{K} 1$ and $\mathrm{K} 2$ changes after 1 month were $>0.05$, which indicates insignificant changes.

Conclusion: The results showed that minimal corneal topographic changes were encountered with the use of TC20V owing to the tunnel configuration of the wound, and these changes also decrease within the first month.

Keywords: TC20V, corneal topography, wound leakage, hypotony

\section{Introduction}

Since the introduction of pars plana vitrectomy, the evolution of instrumentation has been driven by the desire for smaller instruments and greater functionality. Smaller vitrectomy instruments may minimize surgical trauma at the sclerotomy sites, allowing self-sealing sclerotomies, which may improve the surgical efficiency and postoperative recovery. ${ }^{1}$ Transconjunctival sutureless vitrectomy (TSV) with a 23-gauge instrument, introduced by Eckardt in 2005, offers a firmer instrument and supports easier use by the vitreous surgeon who is more familiar with the 20-gauge instrument while giving the same advantages as the 25-gauge instrument with respect to the postoperative corneal changes. ${ }^{2}$ However, both 23- and 25-gauge TSVs were not suitable in some cases, such as in cases when silicone oil is used, as well as the increased financial cost. ${ }^{3}$

Several studies have shown that the corneal contour is significantly changed by 20 -gauge standard vitrectomy, inducing postoperative astigmatism. The induced astigmatism is usually transient and returns to the baseline level by 1 to 
4 months after surgery. The increase in the postoperative astigmatism may be attributed to the scleral cautery and suturing at the entry port. ${ }^{4-6}$ Yanyali et al concluded that regular and irregular astigmatism of the cornea did not change when 25-gauge TSV was used. ${ }^{7}$

Transconjunctival Cannulated 20-gauge vitrectomy (TC20V) is a new technique carrying the advantages of the sutureless techniques, and can be done in almost all cases. In this work, we present the results of the TC20V with respect to the postoperative corneal topographic changes.

\section{Materials and methods}

The prospective randomized controlled study was done at Egyptian Eye Academy (Cairo, Egypt). Randomization included patient selection with respect to indication of vitrectomy. Patients were fully informed of all aspects of the procedure; all provided written informed consent, and ethics committee approval was obtained. The mean age was $53.4 \pm 11.59$ years (range: $25-68$ years); $23(57.5 \%)$ patients were male and $17(42.5 \%)$ were female. TC20V had been done in 40 eyes in 40 different patients for a variety of vitreo-retinal conditions. Corneal keratometric readings were obtained using Oculus Pentacam ${ }^{\circledR}$ (Wetzlar, Germany) before surgery, 1 week, and 1 month after surgery; neither scleral buckling nor silicone oil tamponade were used in order to not affect the final corneal changes.
Cases with postoperative hypotony (ie, postoperative intraocular pressure [IOP] less than $8 \mathrm{~mm} \mathrm{Hg}$ ) were excluded. There were four eyes, and IOP returned to normal levels within 2 weeks.

Exclusion criteria were patients with a history of ocular surgery, those having corneal diseases, severe refractive errors, and significant cataracts. Indications for vitrectomy were proliferative diabetic retinopathy (eleven eyes), macular holes (three eyes), rhegmatogenous retinal detachment (23 eyes), epiretinal membrane (two eyes), and diabetic macular edema (one eye).

The surgical technique consisted of placement of the three sclerotomies at $3.5 \mathrm{~mm}$ behind the limbus in pseudophakic eyes, and $4.0 \mathrm{~mm}$ behind the limbus in aphakic and phakic eyes through the conjunctiva and sclera in two steps. A bent 20G MVR blade (Rochester, NY) was used in a beveled, almost tangential way (15 degrees) to create a combined conjunctivo-scleral tunnel incision; then, the trocar system was introduced. Immediate massage with a cotton tip over the port allowed the scleral flaps of the tunnel to expand and collapse one over the other, which stopped the entry port leak.

\section{Assessment of corneal topography}

Corneal topography was obtained using Oculus Pentacam before surgery, and 1 week, and 1 month after surgery.

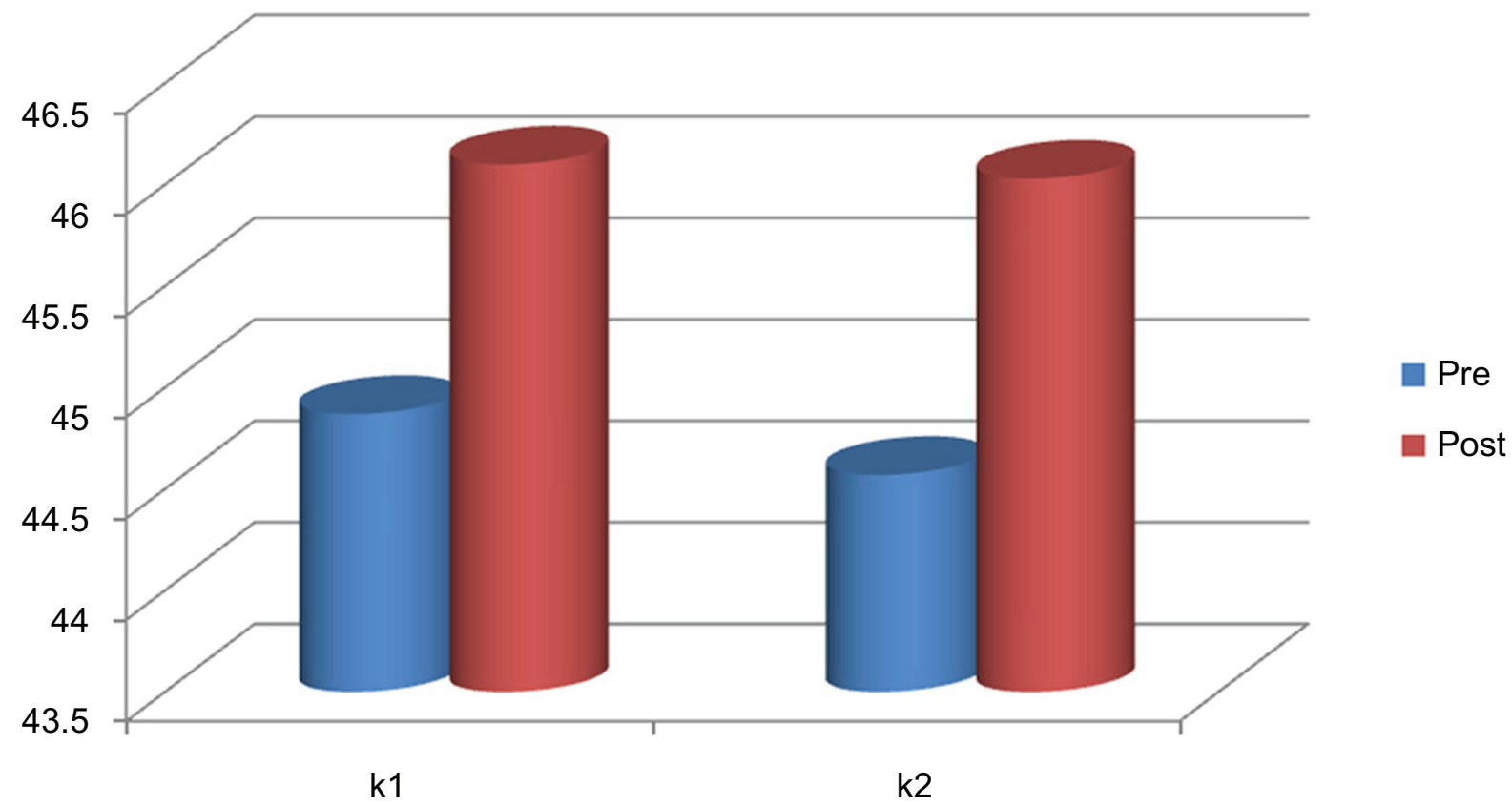

Figure I Mean value of keratometric readings $\mathrm{KI}$ and $\mathrm{K} 2$ pre and postoperative examination.

Abbreviations: pre, preoperative examination; post, postoperative examination; kl, vertical keratometry; k2, horizontal keratometry. 
A

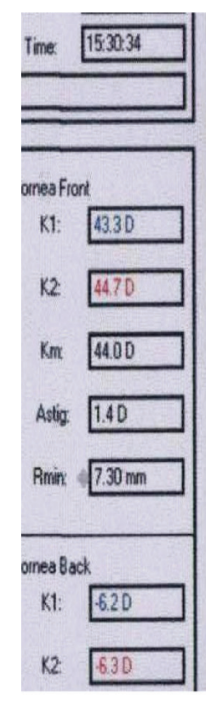

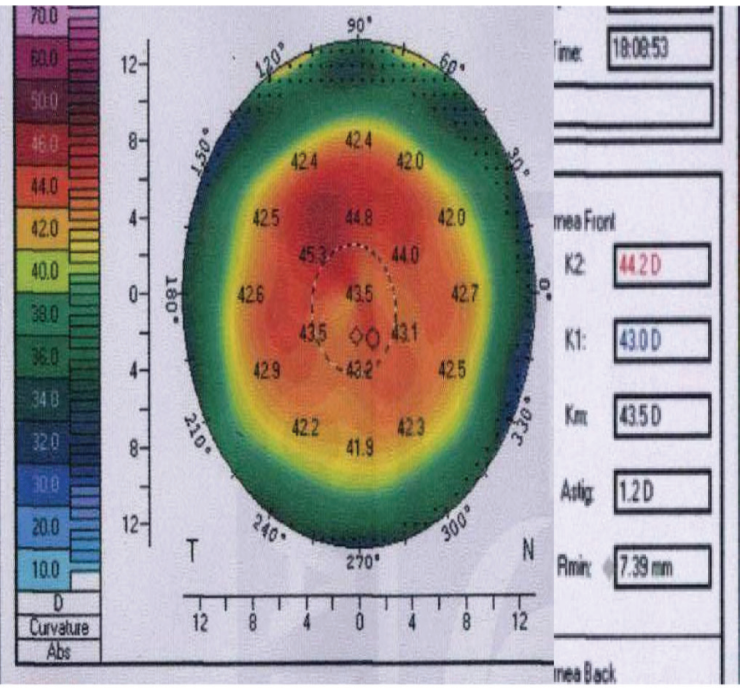

B
C

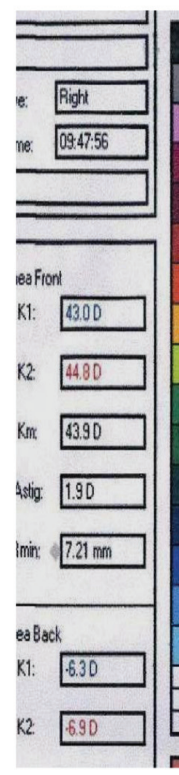

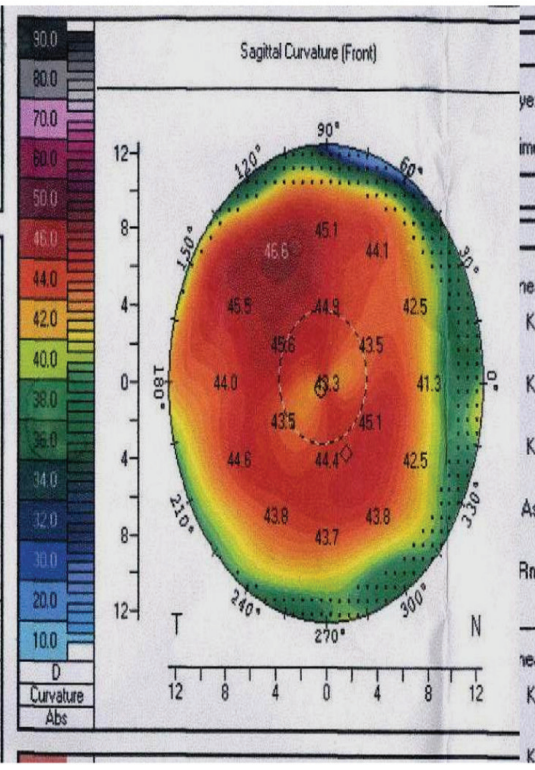

D

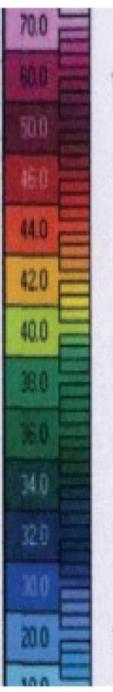

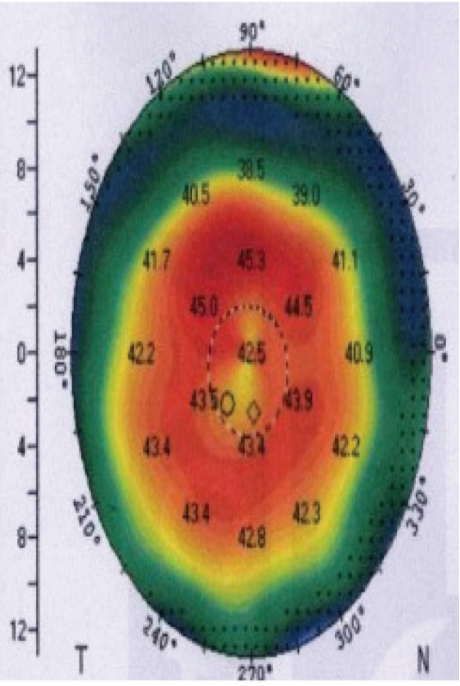

Figure 2 Preoperative (A and $\mathbf{C})$ and postoperative (B and $\mathbf{D})$ changes in two cases.

At each measurement point, three topographic images were obtained, and the best quality measurement was analyzed for regular and irregular astigmatism. Topography data were obtained in a masked fashion by an experienced examiner. K1 (vertical keratometry) and K2 (horizontal keratometry) were used as the preoperative and postoperative comparative measures. $\mathrm{K} 1$ and $\mathrm{K} 2$ were chosen as the parameters of assessment because the main data are obtained by the topographic reading, and irregular astigmatism is unlikely to be found.

\section{Results}

The mean preoperative $\mathrm{K} 1$ was $44.87 \pm 3.55$ and the mean preoperative $\mathrm{K} 2$ was $44.57 \pm 3.68$. The mean postoperative $\mathrm{K} 1$ after 1 week was $45.1 \pm 6.82$ while the mean postoperative $\mathrm{K} 2$ after 1 week was $45.7 \pm 3.97$. Using a paired $t$-test, the $P$-value of the K1 change was 0.01 , and the $P$-value of $\mathrm{K} 2$ change was 0.02 . Both indicated minimal significant differences. At the 1 month postoperative analysis, the mean for $\mathrm{K} 1$ was $45.2 \pm 2.53$ and the mean for K2 was $45.1 \pm 1.56$. The $P$-value of both the $\mathrm{K} 1$ and $\mathrm{K} 2$ changes after 
1 month was $>0.05$, which indicates no significant change. No differences were found in corneal topographic changes between gas-filled and silicone-filled eyes.

\section{Postoperative complications}

Four cases had postoperative hypotony due to wound leaks; two of them needed suturing, and the other two were treated by bandage. Normal IOP was obtained after 2 weeks.

\section{Discussion}

The corneal contour is known to be altered after pars plana vitrectomy (PPV). Domniz et al measured the corneal topography in eyes undergoing PPV by means of videokeratography, and reported that the corneal surface cylinder, average corneal power, regularity index, surface asymmetry index, and irregular astigmatism index were increased at 2 days and 1 week after surgery, but returned to baseline at 1 month after surgery. ${ }^{8}$ Similarly, Wirbelauer et al described a transient increase of keratometric astigmatism at 1 week after PPV; the amount of astigmatic change ranges between 1.5 to 3.0 diopters (D), and returns to the preoperative level at 1 month after surgery. ${ }^{9}$ Tear film dynamics, conjunctival edema, and irritant lacrimal fluid production occurring over several days after surgery may influence the dynamic conditions of the precorneal tear film and, hence, increase the amount of astigmatism. ${ }^{10,11}$

Azar-Arevalo and Arevalo reported a persistent increase in the corneal surface regularity index and surface asymmetry index for more than 6 months after conventional vitrectomy. ${ }^{12}$ However, the number of subjects was limited in their study, and cases undergoing combined scleral buckling, cataract surgery, and silicone tamponade were included. Thus, the influence of vitrectomy alone on corneal topography could not be evaluated. In contrast, because we did not include cases undergoing phacoemulsification and scleral buckling, the current study assessed the influence of vitrectomy per se on the regular and irregular astigmatism of the cornea. The transient corneal surface changes after PPV may be due to corneoscleral sutures; the lyses of the suture after PPV have been reported to reduce postoperative corneal astigmatism by more than $5.0 \mathrm{D} .^{13}$ Bergmann et al reported that scleral cautery near the incisions changed corneal curvature by causing thermal contracture of the treated tissue and immediate central steepening. ${ }^{14}$

In this study, we demonstrated that TC20V does not induce regular and irregular corneal astigmatism, whereas the conventional 20-gauge vitrectomy causes significant alterations in corneal topography. We performed Oculus
Pentacam analyses of corneal topography data to evaluate corneal regular and irregular astigmatism after vitrectomy. Corneal topography was measured one week after surgery when conjunctival edema became undetectable by slit-lamp biomicroscopy and patients' complaints. Therefore, it is unlikely that the tear film dynamics affected the corneal surface conditions. Similar results were obtained using the 25-gauge procedure, and probably resulted in little corneal topographic changes. ${ }^{15}$

TC20V carries advantages over the 25-gauge and 23-gauge procedures by using less expensive instruments, because the instruments were not changed. In 23- and 25-gauge procedures, new instruments were used which are usually more expensive and less durable; the TC20V instruments were suitable for almost all cases, even with silicone oil tamponade. In conclusion, TC20V does not induce significant changes in postoperative corneal topography, and thus, the procedure exerts little influence on the cornea's optical quality.

\section{Disclosure}

The authors report no conflicts of interest.

\section{References}

1. Fujii GY, De Juan E Jr, Humayun MS, et al. A new 25-gauge instrument system for transconjunctival sutureless vitrectomy surgery. Ophthalmology. 2002;109(10):1807-1812.

2. Eckardt C. Transconjunctival sutureless 23-gauge vitrectomy. Retina. 2005;25(2):208-211.

3. Rizzo S, Genovesi-Ebert F, Murri S, et al. 25-gauge, sutureless vitrectomy and standard 20 -gauge pars plana vitrectomy in idiopathic epiretinal membrane surgery: a comparative pilot study. Graefes Arch Clin Exp Ophthalmol. 2006;244(4):472-479.

4. Gotzaridis EV. Three-port 20-gauge transconjunctival pars plana vitrectomy. Retina. 2007;27(3):382-384.

5. Gotzaridis EV. Sutureless transconjunctival 20 gauge pars plana vitrectomy. Semin Ophthalmol. 2007;22(3):179-183.

6. Aguni JS, Meyer CH, Rodrigues EB. Transconjunctival 20-gauge vitrectomy: a pilot study. Ophthalmologica. 2009;223(1):12-16.

7. Yanyali A, Celik E, Horozoglu F, Nohutcu AF. Corneal topographic changes after transconjunctival (25-gauge) sutureless vitrectomy. Am J Ophthalmol. 2005;140(5):939-941.

8. Domniz YY, Cahana M, Avni I. Corneal surface changes after pars plana vitrectomy and scleral buckling surgery. J Cataract Refract Surg. 2001;27(6):868-872.

9. Wirbelauer C, Hoerauf H, Roider J, Laqua H. Corneal shape changes after pars plana vitrectomy. Graefes Arch Clin Exp Ophthalmol. 1998;236(11):822-828.

10. Goto T, Zheng X, Klyce SD, et al. A new method for tear film stability analysis using videokeratography. Am J Ophthalmol. 2003;135(5): 607-612.

11. Kojima T, Ishida R, Dogru M, et al. A new noninvasive tear stability analysis system for the assessment of dry eyes. Invest Ophthalmol Vis Sci. 2004;45(5):1369-1374.

12. Azar-Arevalo O, Arevalo JF. Corneal topography changes after vitreoretinal surgery. Ophthalmic Surg Lasers. 2001;32(2):168-172. 
13. Slusher MM, Ford JG, Busbee B. Clinically significant corneal astigmatism and pars plana vitrectomy. Ophthalmic Surg Lasers. 2002;33(1):5-8.

14. Bergmann MT, Koch DD, Zeiter JH. The effect of scleral cautery on corneal astigmatism in cadaver eyes. Ophthalmic Surg. 1988;19(4): 259-262.
15. Okamoto F, Okamoto C, Sakata N, et al. Changes in corneal topography after 25-gauge transconjunctival sutureless vitrectomy versus after 20-gauge standard vitrectomy. Ophthalmology. 2007;114(12): $2138-2141$.

\section{Publish your work in this journal}

Clinical Ophthalmology is an international, peer-reviewed journal covering all subspecialties within ophthalmology. Key topics include: Optometry; Visual science; Pharmacology and drug therapy in eye diseases; Basic Sciences; Primary and Secondary eye care; Patien Safety and Quality of Care Improvements. This journal is indexed on

Submit your manuscript here: http://www.dovepress.com/clinical-ophthalmology-journal

\section{Dovepress}

PubMed Central and CAS, and is the official journal of The Society of Clinical Ophthalmology (SCO). The manuscript management system is completely online and includes a very quick and fair peer-review system, which is all easy to use. Visit http://www.dovepress.com/ testimonials.php to read real quotes from published authors. 